\title{
Warming soil temperature and increasing baseflow in response to recent and potential future climate change across northern Manitoba, Canada
}

\author{
Rajtantra Lilhare ${ }^{1}$, Stephen Dery ${ }^{1}$, Tricia Stadnyk ${ }^{2}$, Scott Pokorny ${ }^{3}$, and Kristina Koenig ${ }^{4}$ \\ ${ }^{1}$ University of Northern British Columbia \\ ${ }^{2}$ University of Calgary \\ ${ }^{3}$ University of Manitoba \\ ${ }^{4}$ Manitoba Hydro
}

November 5, 2021

\begin{abstract}
This study investigates the impacts of climate change on the hydrology and soil thermal regime of ten sub-arctic watersheds (northern Manitoba, Canada) using the Variable Infiltration Capacity (VIC) model. We utilize statistically downscaled and bias-corrected forcing datasets based on 17 general circulation model (GCM) - representative concentration pathways (RCP) scenarios from phase 5 of the Coupled Model Intercomparison Project (CMIP5) to run the VIC model for three 30-year periods: a historical baseline (1981-2010), and future projections (2021-2050: 2030s and 2041-2070: 2050s), under representative concentration pathways (RCPs) 4.5 and 8.5. The CMIP5 Multi-Model Ensemble (MME) mean-based VIC simulations indicate a $15-20 \%$ increase and $10 \%$ decrease in the projected annual precipitation and snowfall, respectively over the southern portion of the basin and $>20 \%$ rainfall increase over the higher latitudes of the domain by the 2050s. Snow accumulation is projected to decline across all sub-basins, particularly in the lower latitudes. Projected uncertainties in major water balance components (i.e., evapotranspiration, surface runoff, and streamflow) are more substantial in the wetland and lake-dominated Grass and Gunisao watersheds than their eight counterparts. Future warming increases soil temperatures $>2.5^{\circ} \mathrm{C}$ by the $2050 \mathrm{~s}$, resulting in $40-50 \%$ more baseflow. Further analyses of soil temperature trends at three different depths show the most pronounced warming in the top soil layer $\left(1.6^{\circ} \mathrm{C} 30\right.$-year-1 in the $\left.2050 \mathrm{~s}\right)$, whereas baseflow increases substantially by $19.7 \%$ and $46.3 \%$ during the 2030s and 2050s, respectively. These results provide crucial information on the potential future impacts of warming soil temperatures on the hydrology of sub-arctic watersheds in north-central Canada and similar hydro-climatic regimes.
\end{abstract}

\section{Hosted file}

Main_document_Lilhare_et_al.docx available at https://authorea.com/users/444649/articles/ 544341-warming-soil-temperature-and-increasing-baseflow-in-response-to-recent-andpotential-future-climate-change-across-northern-manitoba-canada 